\title{
Constraints on Processes of Diamond Formation from Inclusions in Polycrystalline Diamond (Framesite)
}

\author{
D.E. Jacob ${ }^{1}$, R. Wirth ${ }^{2}$, F. Enzmann ${ }^{1}$, J. O. Schwarz ${ }^{1}$, A. Kronz ${ }^{3}$ \\ 1 Institut für Geowissenschaften, Johannes Gutenberg Universität Mainz, Becherweg 21, D-55099 Mainz, FRG \\ 2 Geoforschungszentrum Potsdam, Telegrafenberg C120, D-14473 Potsdam, FRG \\ 3 Geowissenschaftliches Zentrum der Universität Göttingen, Goldschmidtstr. 1, D-37077 Göttingen, FRG
}

Polycrystalline diamond aggregates occur in a few (but not all) kimberlite pipes in southern Africa (e.g. Venetia, Premier, Jwaneng, Orapa) and can make up several percent of the diamond production in a mine. They are classified by increasing grain size as framesite (Gurney and Boyd, 1982) or boart (Orlov, 1977) and typically have a porous structure that indicates formation from $\mathrm{C}-\mathrm{H}-\mathrm{O}$ fluids rather than from melts. The diamond aggregates can contain silicates of eclogitic and peridotitic affinity, similar (but not identical; Sobolev et al., 1975) to the inclusion suite found in gem-sized diamonds. The minerals occur mostly in interstices and are intimately intergrown with the diamonds, which, in addition to further structural and geochemical evidence (e.g. Jacob et al., 2000, 2004; Kurat and Dobosi, 2000) indicates contemporaneous crystallization within the diamond stability field in the Earth's mantle.

In addition to silicates, rarer phases such as Fe-carbide can sometimes be found in framesites that record unusually low local oxygen fugacity at the time of their formation (Jacob et al. 2004). Furthermore, while most gem-sized diamonds have old, often Archaean formation ages, polycrystalline diamond aggregates from the Venetia Diamond Mine (South Africa) containing eclogitic minerals have been shown to form by very young remobilization processes within the cratonic lithosphere that directly preceded kimberlite eruption (Jacob et al., 2000). Thus, these samples may provide a unique source of information on the nature and timing of small scale processes that lead to diamond formation which complements evidence from gem-sized diamonds.

Recently, new insight into diamond formation processes came from Transmission Electron Microscopy (TEM) combined with sample preparation techniques using a focussed ion beam (FIB) of Gallium ions applied to micro- and nanometre-sized inclusions in diamond that were previously hardly accessible to study (e.g. Klein-BenDavid et al., 2007, Logvinova et al., 2008). Up to now, these studies concentrated mainly on fibrous diamonds and revealed the presence of multi-phase assemblages of carbonates, halides, apatite, silicates and fluids. These phases are interpreted to be the low PT products of the supercritical fluid from which the diamonds formed.

Using the TEM/FIB method, we present here the first study of micro- and nano-inclusions in diamonds from a polycrystalline diamond aggregate (framesite) from the Orapa Mine (Botswana) and combine results from TEM/FIB analyses with high-resolution computerized micro-tomography (HR- $\mu \mathrm{CT}$ ) and electron microprobe analyses to further constrain the formation of diamond in the Earth's mantle.

\section{Sample and Analytical Methods}

The sample PHN 4596/22 stems from a collection of P. Nixon from the Orapa kimberlite pipe and is about one centimetre in size. Diamond is very fine-grained (less than $1 \mathrm{~mm}$ on average). The sample contains a number of black to reddish inclusions at the surface and is magnetic. After cutting and polishing (carried out at the Research Laboratory of the De Beers Diamond Trading Company, Maidenhead, UK), the sample was mounted in epoxy and major element analyses of the inclusions were carried out using JEOL 8900R electron microprobes at the University of Göttingen and the University of Mainz. by wavelength-dispersive analysis with a beam diameter of $2 \mu \mathrm{m}$. Standardization was carried out with a range of natural and synthetic standards and the data were corrected using the CITZAF procedure.

Micro-Computer-Tomography was carried out using a CT-alpha instrument (Procon X-ray) with a spatial resolution of $1 \mu \mathrm{m}$ per voxel (volume per pixel) at the Department of Geosciences at the University of Mainz. The sample was irradiated with a white X-ray cone beam (acceleration voltage of $60 \mathrm{kV}$, tube current of $250 \mu \mathrm{A})$. The X-ray beam is pre-filtered by an aluminium foil with a thickness of $0.15 \mathrm{~mm}$. Projections are taken with an integration time of $1.5 \mathrm{~s}$. For the measurement, 800 projections were acquired during a $360^{\circ}$ rotation of the sample.

For Transmission Electron Microscope analyses (TEM), twelve ultra-thin foils of ca. 10 by $15 \mu \mathrm{m}$ and $0.150-0.200 \mu \mathrm{m}$ thicknesses were prepared from the polished surface using the focussed ion beam device (FIB) of a FEI FIB200 instrument following procedures given by Wirth (2004). The surface was 
then re-polished and a further three foils were cut from the newly exposed surface. After milling, the foil was cut free, extracted, and placed on a carbon coated $\mathrm{Cu}$ grid. No further carbon coating was necessary. TEM imaging and analysis were undertaken with a FEI Tecnai ${ }^{\mathrm{TM}} \mathrm{G} 2$ F20 X-Twin transmission electron microscope with a FEG electron source. The TEM was operated at $200 \mathrm{kV}$ acceleration voltage. A Gatan Tridiem $^{\mathrm{TM}}$ filter allowed energy-filtered imaging applying a $20 \mathrm{eV}$ window to the zero loss peak. Analytical electron microscopy (AEM) was performed with an energy dispersive X-Ray analyzer (EDX). Analyses usually were carried out in scanning transmission mode (STEM) scanning the beam in a pre-selected window thus avoiding mass loss during the spectrum acquisition. Counting time was 60-120 seconds. Beam size was approximately $1 \mathrm{~nm}$ in diameter. Images in the STEM mode were acquired with a high angle annular dark filed detector (HAADF).

\section{Results}

\section{Macroinclusions}

Macroinclusions larger than ca. $5 \mu \mathrm{m}$ in diameter were identified at the polished surface of the sample compositionally by electron microprobe and structurally by their d-spacing measured by TEM. Most prominently, the sample contains abundant magnetite (4.8 $\AA$ (111), $3.04 \AA$ (022), $2.55 \AA$ (113)) that is often surrounded by hematite (2.69 $\AA$ (104), $2.48 \AA$ (110), 3.74 (012)). Additionally, FeS, low-Cr garnet $\left(\mathrm{Py}_{50} \mathrm{Alm}_{39} \mathrm{Grs}_{11}\right)$ and omphacite $\left(\mathrm{Jd}_{23}\right)$ were detected in the interstices. Garnet and cpx were found as discrete, non-touching inclusions. Applying the Mg-Fe exchange thermometer (Ellis and Green 1979) to garnet and cpx yields a temperature of $1256^{\circ} \mathrm{C}$ at an assumed pressure of $5 \mathrm{GPa}$. Most of the magnetite inclusions are single crystals, some, however, are strongly deformed and show signs of recrystallization. Hematite occurs as

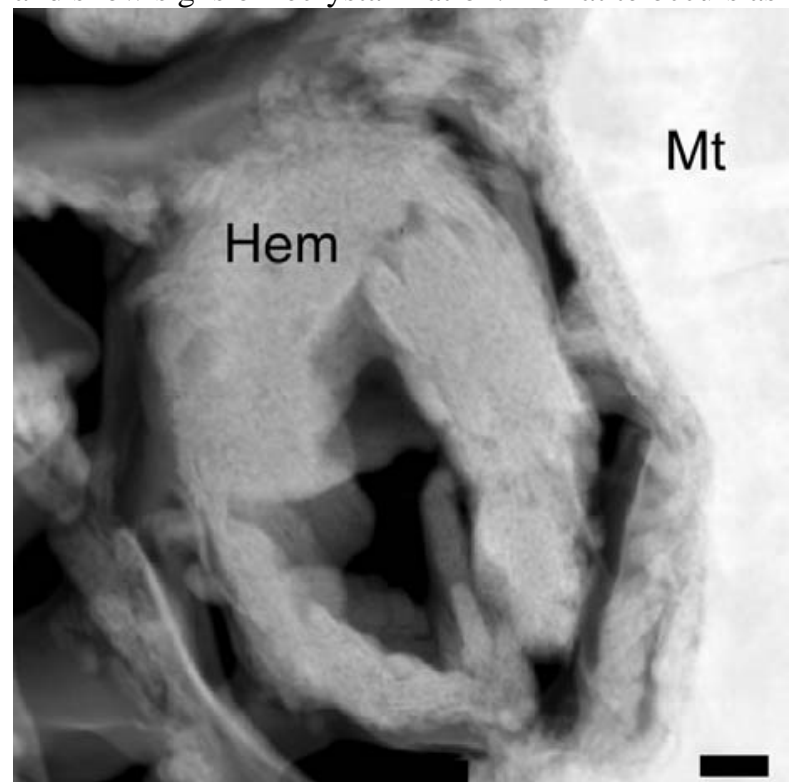

Fig. 1: HAADF TEM image of porous aggregates of hematite (Hem) adjacent to magnetite (Mt). Scale bar is $100 \mu \mathrm{m}$. porous aggregates (Fig. 1), consisting of nano-granules of ca. 5-7 nm sizes.

High Resolution $\mu$-Computer Tomography (HR- $\mu \mathrm{CT}$ ) shows pores in the sample as well as the different included phases as areas of differing grey-values (Fig. 1 ). These are a direct function of the specific x-ray density of the specific phase. Magnetites can therefore be identified in the tomogram as bright areas (Fig. 2a), while silicates are of a darker shade of grey. Based on the 3D tomogram, the amount of pores (blue in Fig. 2b) per total volume of the diamond plus inclusion matrix is calculated to be 0.65 vol\%, while magnetite inclusions (green in Fig. 2b) amount to 3.16 vol\%. The average equivalent radius of the magnetite grains (radius of a sphere with the same volume as the grain) is $17.8 \mu \mathrm{m}$, while that of the pores is $12.6 \mu \mathrm{m}$.

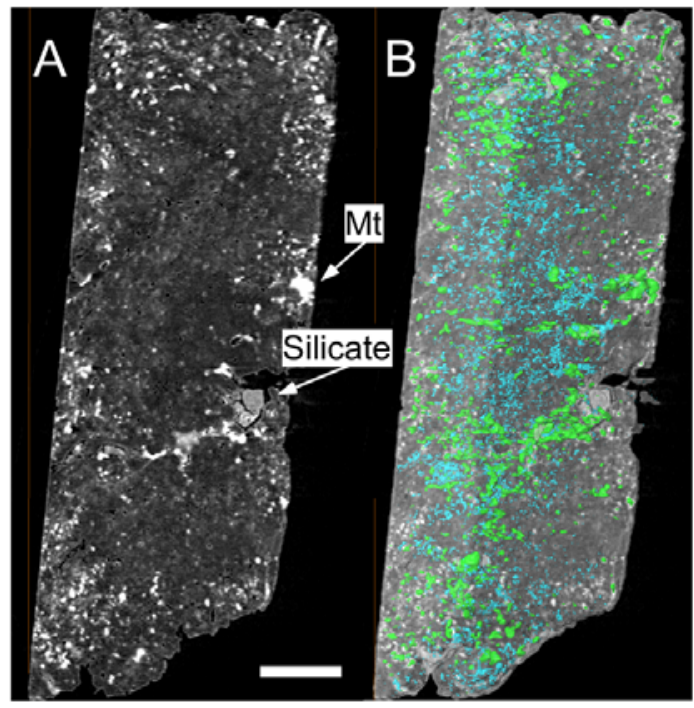

Fig.2: Micro-Computer-Tomogram of the diamond sample. (A) shows a 2-D slice through the sample in which multiple magnetite inclusions (light phase) and one large silicate inclusion (grey phase) can be recognized. (B) is the same view as A overlain by a 3D view that shows the pores (blue) and the magnetite (green) distribution. Scale bar is $1 \mathrm{~mm}$.

\section{Microinclusions}

In total, 14 microinclusions from fifteen foils were investigated. Micro- and nano-inclusions identified by TEM were smaller than $1 \mu \mathrm{m}$ down to ca. $50 \mathrm{~nm}$ in size; both monomineralic as well as multi-phase inclusions could be identified. The cavities are often lath-shaped and oriented parallel to each other; many show lattice dislocations in the surrounding diamond. In addition, inclusions are found along open cracks within the diamond single crystals. Mineral phases in the microinclusions comprise rutile, omphacite and an FeS phase. d-spaces measured for the FeS phase gave $5.6 \AA$ and $2.08 \AA$ which suggest that this phase is most likely pyrrhotite. Omphacite was identified based on measured d-spaces of $5.18 \AA$ (101), $4.55 \AA$ (020), 3.4 $\AA$ (121) as well as its chemical composition determined by AEM. The chemical composition of the omphacite microinclusions is very similar to that of the omphacite macroinclusions. However, in contrast to the macroinclusions, magnetite, hematite and garnet were 
never encountered as microinclusions. The multiphase inclusions most often consist of cavities that are only partly occupied (to less than $50 \%$ of the total space) by one ore more of the mineral phases listed above, suggesting that the empty space was originally filled by a fluid. In fact, one multiphase inclusion was found to be still fluid-bearing (Fig. 3), showing characteristic continuous changes in diffraction contrast due to density fluctuations caused by the electron beam. No other elements than carbon were detected during AEM of this area which suggests that the fluid consists of relatively pure $\mathrm{C}-\mathrm{H}-\mathrm{O}$ species. In addition to the fluid, this inclusion contained fine-grained $\mathrm{FeS}$, a silicate phase rich in $\mathrm{Fe}, \mathrm{P}, \mathrm{Mg}, \mathrm{Al}, \mathrm{Ca}$ and $\mathrm{K}$ and a quench phase, rich in $\mathrm{Fe}, \mathrm{P}$ and $\mathrm{Si}$.

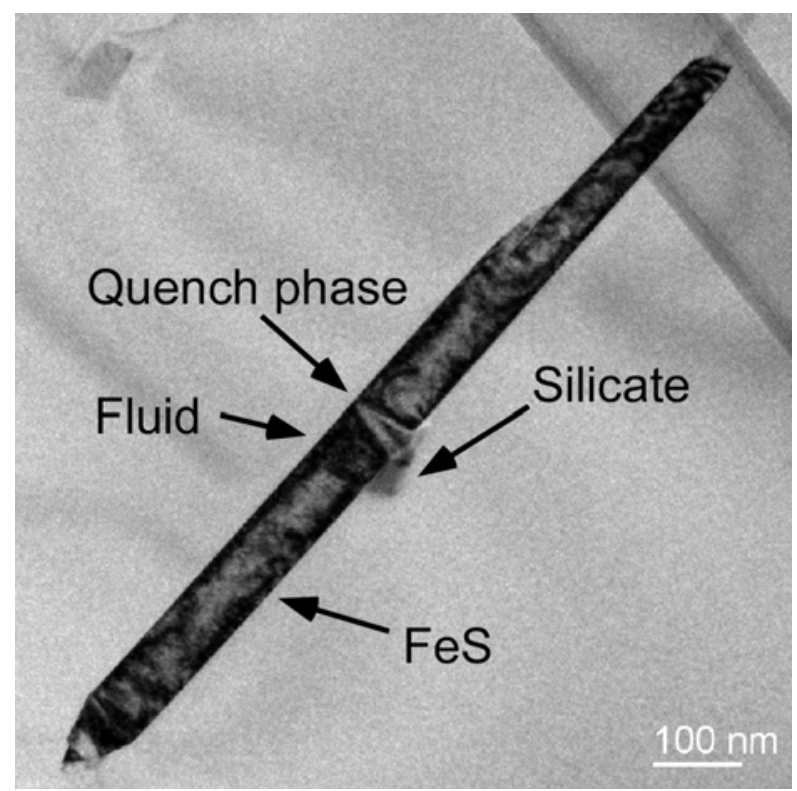

Fig. 3: Bright Field TEM image of a fluid-bearing microinclusion. Dark band in the upper right is the carbon grid supporting the sample.

\section{Discussion}

The inclusion paragenesis of this polycrystalline diamond aggregate clearly indicates an eclogitic affiliation. It is interesting to note, however, that not all inclusions are found as macro- and as microinclusions in the sample. Magnetite, hematite and garnet are only identified as macroinclusions, rutile is restricted to microinclusions, while omphacite and FeS can be found at both scale ranges. Although it is difficult to evaluate how representative the fourteen inclusions studied by TEM are for the entire inclusion suite of the framesite sample, the occurrence of omphacite, rutile and $\mathrm{FeS}$ as microinclusions within the diamond crystals clearly shows that these phases are cogenetic to the diamonds. Magnetite and hematite, on the other hand, were only encountered as large inclusions in cavities that appear to be interstitial porosity. Moreover, analysis of the equivalent radius distribution of the pores and the magnetite inclusions derived from HR$\mu \mathrm{CT}$ shows a complete overlap of the mode, indicating that magnetite preferentially fills the porosity in the sample. Furthermore, hematite occurs exclusively along the outer rim of the magnetite crystals and textural features (Fig. 1) suggest that this phase is a late replacement product of magnetite. This shows that the magnetite-bearing cavities were not shielded from the outside by the host diamond and may indicate that magnetite itself was introduced after diamond formation or during a secondary event that may still, however, have taken place at PT conditions of the diamond stability field.

Most importantly, the microinclusion suite described here is distinct from that found in fibrous (KleinBenDavid et al., 2007; Logvinova et al., 2008) and in microdiamonds (Kvasnytsya et al., 2005, 2006). Carbonates, halides and phosphates, that are typical for fibrous and microdiamonds were not encountered in our study. Instead, the microinclusion suite found in the framesite consists of the typical eclogitic minerals (rutile, garnet, omphacite, sulphide) plus a C-H-O fluid.

\section{References}

Ellis, D.J. and Green, D.H., 1979. An experimental study of the effect of Ca upon garnet-clinopyroxene Fe-Mg exchange equilibria. Contributions to Mineralogy and Petrology, 71: $13-22$.

Gurney, J.J. and Boyd, F.R., 1982. Mineral intergrowths with polycrystalline diamonds from the Orapa Mine, Botswana. Yearbook Carnegie Institution, 267-273.

Jacob, D. E., Kronz, A., Viljoen, K.S., 2004. Cohenite and native iron inclusions in garnets from polycrystalline diamonds. Contributions to Mineralogy and Petrology, 146, 566-576.

Jacob, D. E., Viljoen, K. S., Grassineau, N., Jagoutz, E., 2000. Remobilization in the cratonic lithosphere recorded by polycrystalline diamond (Framesite). Science, 289, 11821185.

Klein-BenDavid, O., Wirth, R. and Navon, O., 2007. TEM imaging and analysis of microinclusions in diamonds: A close look at diamond-growing fluids. American Mineralogist 91, 353-365.

Kurat, G. and Dobosi, G., 2000. Garnet and diopside-bearing diamondites (framesites). Mineralogy and Petrology, 69: 143159.

Kvasnytsya, V.M., Taran, M.M., Wirth, R., Wiedenbeck, M., Thomas, R., Lupashko, T.M., Il'chenko, K.C., 2005. New data about Ukrainian diamonds. Mineralogical Journal (Ukraine) 27 (4), 47-58.

Kvasnytsya, V.M., Wirth, R., Thomas, R., Taran, M.M., 2006. Microinclusions in the diamonds of the Samotkan region and their origin. Ukrainian Geologist 2, 25-36.

Logvinova, A.M., Wirth, R., Fedorova, E.N., Sobolev, N.V., 2008. Nanometre-sized mineral and fluid inclusions in cloudy Siberian diamonds: new insights on diamond formation. European Journal of Mineralogy 20 (3), 317-333.

Orlov. J. L., 1977. The mineralogy of diamond. Wiley, New York, $235 \mathrm{pp}$.

Sobolev, N. V., Pokhilenko, N. P., Lavrent'ev, Y. G., Usova, L. V., 1975. Distinctive features of the composition of chrome spinels in the diamonds and kimberlites of Yakutia. Soviet Geology and Geophysics, 16 (11), 7-24. Wirth R., 2004. Focused Ion Beam (FIB): A novel technology for advanced application of micro- and nanoanalysis in geosciences and applied mineralogy. European Journal of Mineralogy 16, 863-876. 